\title{
EVALUATION AND CONTROL OF MARINE VESSELS STABILITY IN WAVES
}

\author{
*R. Ferreiro García, **C. Antonio F. Ameal \\ Universidad de A Coruna, *Dep. Industrial Eng. ${ }^{* *}$ Dep. Navigation and Earth Sciences \\ E.S.M.C. Paseo de Ronda, 51, 15011 A Coruna, Spain \\ Tel.: 3481167000 ext.4205, Fax.:34 81 167101, ferreiro @udc.es
}

\begin{abstract}
This paper presents the research results achieved by means of the preliminary design study and implementation of a Pc-based Expert System for Safely Navigation. PESSN. It consists in an advisory system related to the stability and motion of the vessels in waves, where environmental information and marine vehicle conditions are acquired by a set of sensors. A proper real time corrective action is taken by means of PESSN. . Copyright @ 2000 IFAC
\end{abstract}

Keywords: Stability on waves, Human factor, FFT, Risk evaluation, Rule based system

\section{INTRODUCTION: PROBLEM STATEMENT}

Stability safety is a very complex problem in which not only the inherent features of a ship but also the action of her crew determine whether the ship will survive in critical conditions. The skills of the crew and their correct reaction in a dangerous situation may well decided between survival and disaster. The human factor should be always taken into consideration in the overall analysis of safety against capsizing. All intact stability requirements by regulatory or ship stability booklets, have been supplemented by some paragraphs related to operational aspects of stability safety, as for instance,"Masters should therefore exercise prudence and good seamanship..." but presently stability standards, like IMO code, do not provide any direct indication of how the dynamic of a ship in waves would decrease stability safety, and in addition to prudence and good seamanship, the Master need such information in order to make correct decisions. Although a "Guidance to the Master for avoiding dangerous situation in following and quartering seas", had been developed, and at the same time, a meteorological stability criteria had been applied to increase the safety, at least, in beam waves, although every type of marine vehicle has her own dangerous combination of speed, course angle, loading conditions and critical environmental parameters.

The actual development and introduction of new and revolutionary tyPESSN of marine vehicles, with increments in size and speed, together with an increase in shipping industry pressure over reduced and sometimes fatigue crews, due the own internal dynamics of strongly competence between companies in actual air and maritime commercial world, makes necessary the introduction on board of an intelligent expert system, with adaptive state of the art Knowledge, KBS, derive from human expertise, experiments and theoretical research, to identify and validate in advance risk factors, possible dangerous scenarios and manoeuvring decisions always in heavy weather conditions, when everybody could be imposing a large responsibility upon the master of the ship, that may be is compulsory to maintain speed and course in any conditions.

Nowadays and more in a short future, navigators need more and new information, because "the rules 
of thumb" of the traditional shiphandling knowledge accumulated in expertise shipmaster know-how, or expressed in technical and traditional shiphandling books through years, could be out of phase with the characteristics and requirements of new ships and maritime traffics. These asseverations are based in the classical concept of that experience, which are based on "feel of the ship", when the mariner knew that by different manoeuvres they were able to reduce the risk of dangerous ship motions, as judged from their feel of the situation acquired mainly by trial and error in conventional ships. Nevertheless, it appears that nowadays this is not enough to assure ship safety against capsizing in waves, to avoid severe cargo damage, or even structural failure, because in a different ship could not be true that risk was reduced to tolerable values due to that control action, with only the basic sentence "reduce speed, and/or, change course”.

The variety and number of possible criteria as well as possible scenarios, the inherent variability characteristics of the actual and in development ship-fleet, demands an effort from all statements of maritime authorities to prevent future disasters due a lack of actual prevision from the first level of training, to the regulatory codes and resolutions imposed to the future shipmasters, maybe without enough seaways experience, or with misleading in ship behaviour in waves. The reliability of ship and of ship's system has a major impact in safety and costs for shipping, but in this industry highly regulated which has addressed safety from a technical viewpoint and, historically, has adopted a reactive approach to safety, i.e. safety improvements always followed an accident. During the last years and especially in view of some tragic accidents involved passenger ferries those issues have became more and more important.

In this context PESSN system, permit a real time evaluation and control, of the vessel operational safety in waves, if necessary without human supervision, also with the possibility of integration in a full shipboard information, decision support and control system minimising heavy weather risks and damage, as well as a necessary increase of general operational performance of the ship in a seaway.

\section{BASIC FUNCTIONS OF PESSN}

The PESSN is an onboard real time expert system that provides information, decision support or included ship control in heavy weather situations. PESSN can also be used in normal or critical situations to provide at officer of the watch with simulations of the effect of changes in ship control conditions, on capsize risk index, Ic, and in upcrossing fixed thresholds probability by roll or pitch motions or assessing ship operational performance in the seaway.

Sailing in any conditions, initial static stability index, GM, can be check-up by means of roll period estimation from roll motion measurements an its FFT processing, taking account of period change with roll maximum amplitude in hard or soft righting lever curves as well as typical S curves of static stability. Then, the aim of the system is to help the helmsman to decide on an appropriate course of action based on environment information. All suggested action also includes information regarding the conditions that makes the vessel unsafe. The main functions of PESSN are outlined below as,

- Real time data acquisition.

- Decision making.

Figure 1 shows the general context in which PESSN operate.

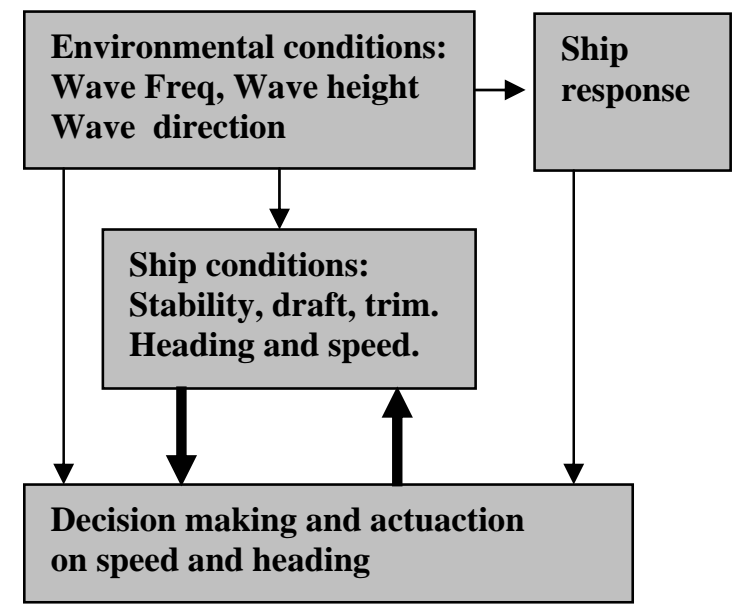

Fig. 1. The fundamental PESSN structure.

\subsection{Real time data acquisition}

This is basically a measurement subsystem for data acquisition that makes the same functions of a set of PC-peripherals. The main control parameters are ship course and speed which could be obtained online with sea-reference from gyrocompass and log, together with earth-reference data from GPS navigation system. An X-band nautical Radar for incident wave field could supply the wave characteristics like direction and height. Direction and height could also be supplied by manual means by acquiring such data from the Oceanweather's Global Forecast valid for a day. Roll motion measurement is based in accelerometers or a strap down inertial system, with the possibility of estimation the full wave field around ship, and evaluation and control of the initial static stability index. 


\subsection{Calculation subsystem}

In this subsystem incident wave field estimation from image processing techniques of nautical radar or manual data supplying, permit obtain one of the most important data sets for PESSN, the sea or swell main direction and its dispersion coefficient, supplying also the modal frequency of wave spectrum, the maximum energy wavelength, and the significant wave height. From such data, it could be calculated modal wave slope, wave celerity, and characteristic wave group speed. Relative angle to waves is calculated from ship course, with a convention of $0^{\circ}$ course sailing in following waves and $180^{\circ}$ sailing with head waves. From the ship-motion measured data, computation of motions amplitude, as well as estimate expected maximum motions value, natural frequencies, and probability of motions exceeding a limit value in a certain time.

\subsection{Knowledge based system}

Navigation in heavy weather is a source of risk. The KBS is developed in order to achieve a capsizing risk index Ic, for each environmental and ship cargo situation, processing available information from ships model essays, simulation programs, human experts, theoretical developments, reference and regulatory bibliography. Following this expert information a number of possible dangerous scenarios is also included, like harmonic or subharmonic resonance situations, or sufficient conditions for surf-riding or broaching.

\subsection{Decision Making}

The inference engine analyse characteristic wave values with its ship motion and static parameters, like speed, length, or natural roll period with wave encounter period from absolute wave modal period, ship speed and relative angle between both. The objective is to minimise Ic. If a fixed Ic is demanded, then it will be computed the safe domain of ship headings and speeds, and also if a capsize standard scenario is detected, it advices or suggest the necessary manoeuvring (speed and/or heading), to avoid it, all from the information stored in KBS. Alarms are always visually and audibly presented.

\section{SIMULATION RESULTS}

PESSN has been in a simulated environment, and results are graphically achieved. In figure 2 a layout of the graphical interface to know maximum safe speed at fixed Ic and relative angle to waves, in following to quartering seas is shown for a specified fast container ship sailing in a prefixed sea state.

In figure 3 it is shown a layout of the graphical interface to test different ships size, Ic for different environmental conditions and resonant possibilities. In order to update the KBS, the graphical interface permits the introduction of ship length, beam and draft to select ship dimensions, constrained to the main typical relations concerned to fast container ships(beam to draft ratio). Input parameters are

Ship speed, GM, wave period, the possibility of a selected risk index Ic, and tolerance of encountering frequency for resonance included. The screen shows alarms for Ic limit, and harmonic and sub-harmonic resonance.

IMO guidance introduce some constraints to ship speed and ship course, based in standard risk situations for every ship as a function of ship wavelength ratio, significant wave height and wave period. Such restrictions are shown in figure 4 including the possibility of input specific wave length as described below: risk is high when wavelength $>0.8$ Shiplength and significant wave height $>0.04$ Shiplength, or ship speed is around 0.3 froude number, always that ship course relative to waves is between $0^{\circ}$ and $45^{\circ}$. (Following or quartering waves). Alarms are activated to advice on dangerous quartering waves.

\subsection{A particular application}

A particular application is shown al table 1 and table 2, in which for a containership of given characteristics under a sea wave condition it is observed that for a speed of $10.5 \mathrm{~m} / \mathrm{sec}$. And wave ang of 18 deg. A risk index of 0.2 is achieved. Increasing ship velocity towards $12.5 \mathrm{~m} / \mathrm{sec}$, the risk index increases till 0.5 , which is drastically dangerous. Then changing the ship course till wave ang. 60 deg., then, risk index decreases to nearly zero.

Table 1. Ship anad Environment characteristics

\begin{tabular}{|l|l|}
\hline Ship Characteristics & Wave Characteristics \\
\hline Length $=136 \mathrm{~m}$ & Wave ang. $=18 \mathrm{deg}$. \\
\hline Beam $=22 \mathrm{~m}$ & Wave period = 9 sec. \\
\hline Draft $=8.4 \mathrm{~m}$ & $\mathrm{H}(1 / 3)=4 \mathrm{~m}$ \\
\hline $\mathrm{GM}=1.2 \mathrm{~m}$ & \\
\hline
\end{tabular}

Table 2.Results using the PESSN

\begin{tabular}{|l|l|l|}
\hline vel.(m/sec) & Wave ang. & Risk Index \\
\hline 10.5 & 18 & 0.2 \\
\hline 12.5 & 18 & 0.5 \\
\hline 12.5 & 60 & 0.1 \\
\hline
\end{tabular}




\section{CONCLUSIONS}

The focus of PESSN is primarily to enhance crew performance and thereby safety, rather than reducing the crew size further for actual or future ships. The system has been tested in a simulated environment according well contrasted models of fast ships, mainly container vessels and fast ferry. It appears to be that after this initial test, it supposes the preliminary step of a ongoing project for full management of marine vehicles safety, and that there is a large demand for more precise knowledge about how the ship is going to respond after changes in speed and course, mainly in fast sealinks, therefore the future final users.

\section{REFERENCES}

IMO, (1993), Resolution A.749 (18),"Code on intact stability for all ty PESSN of ships covered by IMO instruments”.

IMO, (1993), Model Course 7.01,"Master and Chief Mate”.

IMO, (1995), MSC/Circular 707,"Guidance to the master for avoiding dangerous situations in following and quartering seas".

G.Danton, (1987), "The Theory and practice of Seamanship", 10th ed., textbook, pages 200-211, Management and Handling of Ships in Heavy Weather and the use of Oil, (6 hours of theory inshore).

IMO, (1995), STCW Convention

Nieto Borge, J.C., Hessner, K., Richert, K. (1999),"Estimation of the Significant Wave

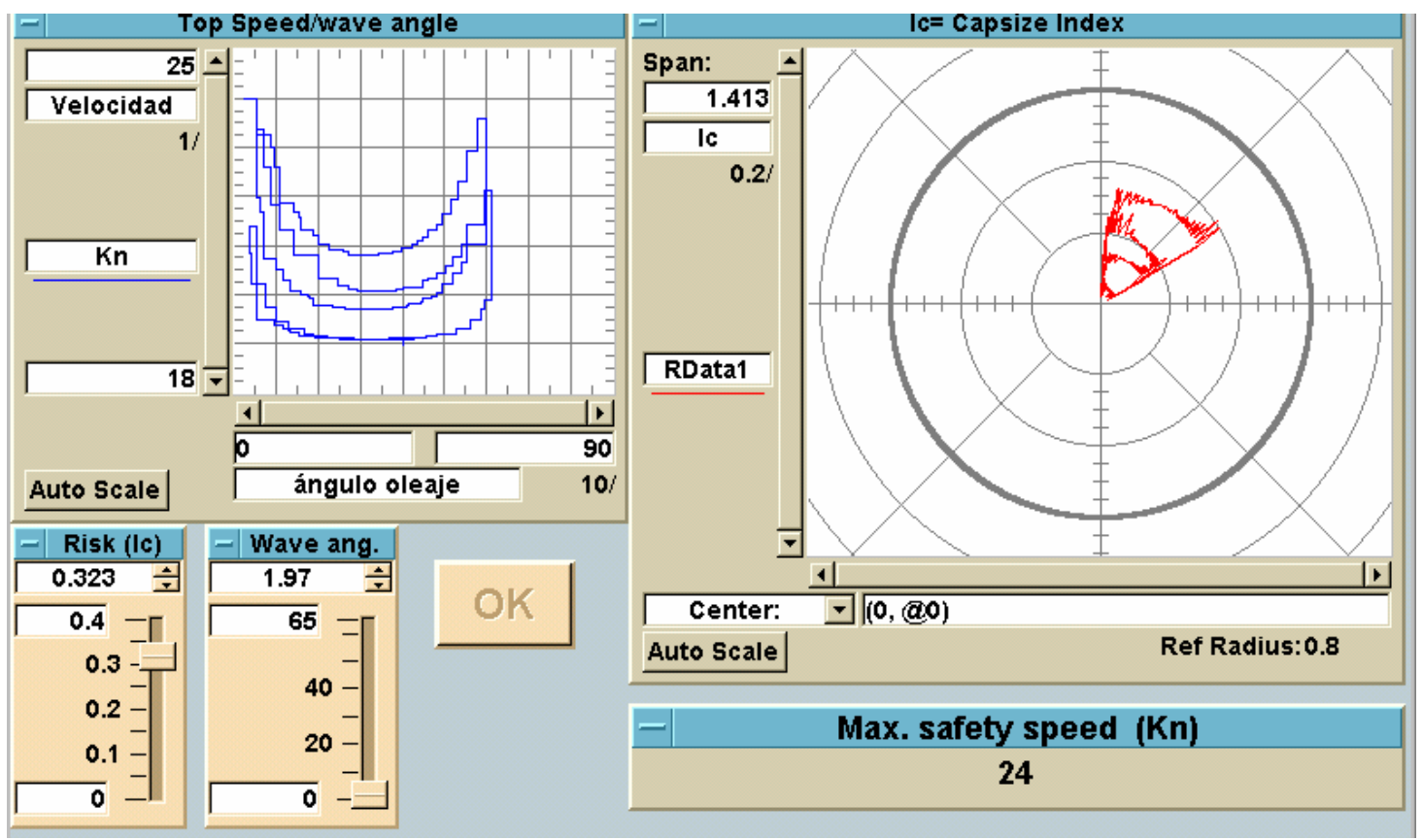

Fig. 2. The Maximum safe speed at a fixed Ic 


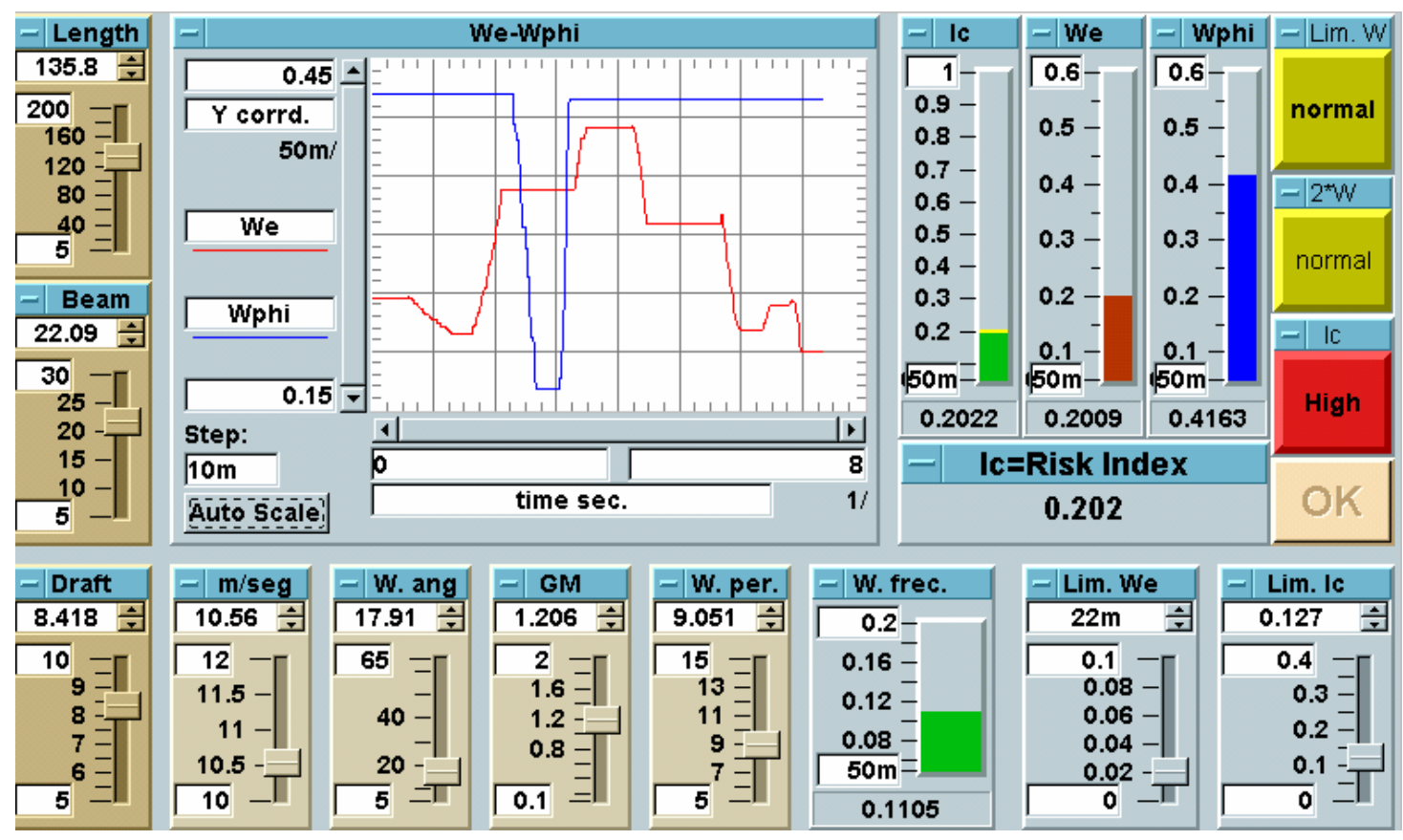

Fig. 3. The test of different ship size, Ic for different environmental conditions and resonant possibilities.

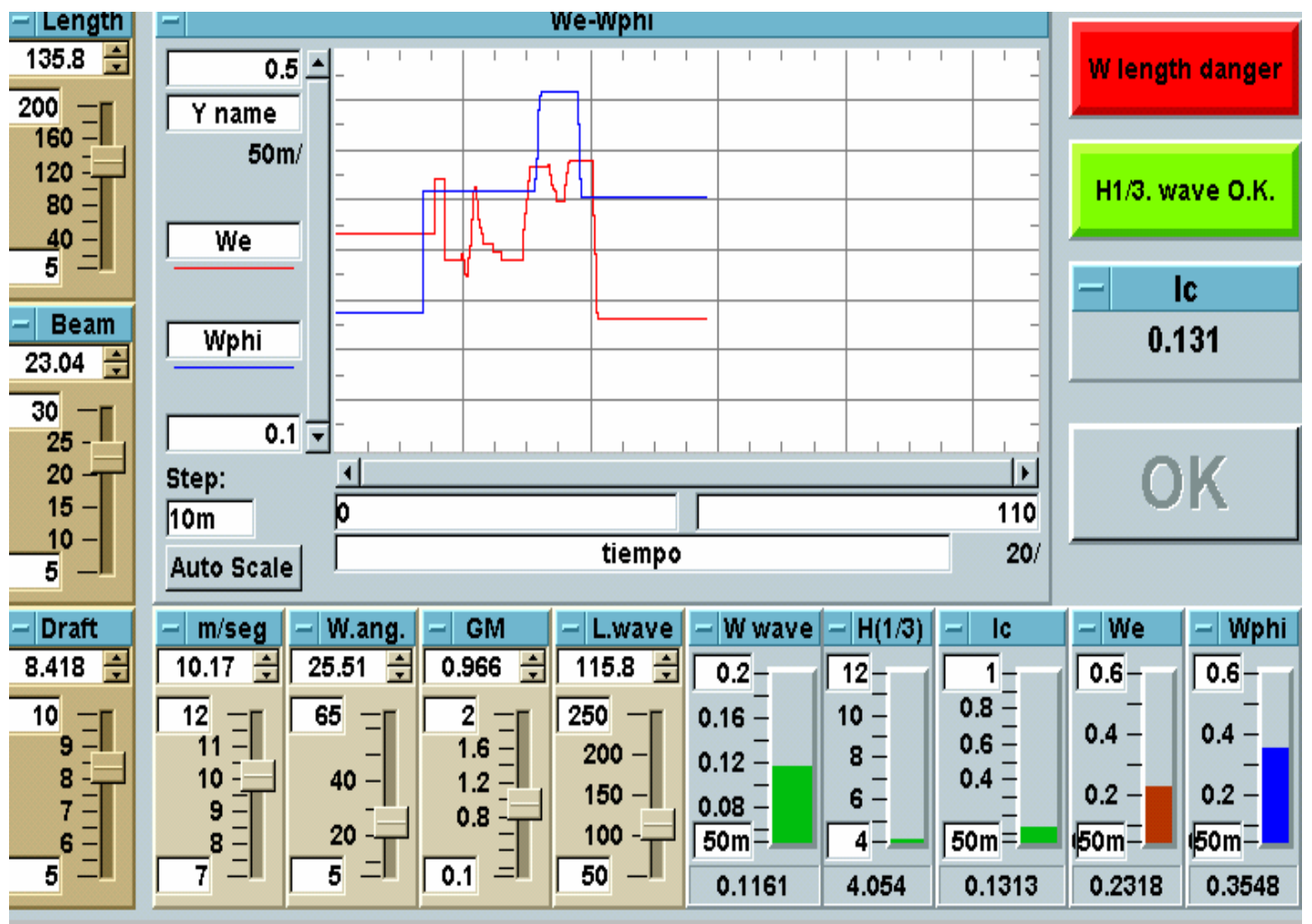

Fig 4. Graphical interface of PESSN taking into account the IMO guidance 